\title{
Shear Performance Assessment of Timber Log-House Walls under In-Plane Lateral Loads via Numerical and Analytical Modelling
}

\author{
Martina Sciomenta ${ }^{1,+}$, Chiara Bedon ${ }^{2, *,+(\mathbb{D})}$, Massimo Fragiacomo ${ }^{1(\mathbb{D})}$ and Angelo Luongo ${ }^{1 \oplus}$ \\ 1 Department of Civil, Architecture and Building and Environmental Engineering, University of L'Aquila, \\ Via Giovanni Gronchi 18,67100 L'Aquila, Italy; martina.sciomenta@graduate.univaq.it (M.S.); \\ massimo.fragiacomo@univaq.it (M.F.); angelo.luongo@univaq.it (A.L.) \\ 2 Department of Engineering and Architecture, University of Trieste, Piazzale Europa 1, 34127 Trieste, Italy \\ * Correspondence: chiara.bedon@dia.units.it; Tel.: +39-040-558-3837 \\ + Joint first authorship.
}

Received: 30 June 2018; Accepted: 31 July 2018; Published: 1 August 2018

\begin{abstract}
Log-house is an ancient construction technology based on the superposition of linear timber logs, connected to the orthogonal walls by a system of carvings, notches and corner joints. Due to the fact that this solution is widely used in constructions located in seismic or windy areas, the in-plane behaviour of walls represents an attractive research topic. In this paper, major outcomes of a Finite-Element (FE) numerical investigation carried out on single corner joints currently in use for log-house buildings are discussed under different loading conditions (i.e., in-plane lateral and vertical compressive loads), including parametric analyses to capture the key aspects of their typical structural response. Careful consideration is paid for the elastic stiffness of such joints, being of primary interest for design purposed. At the same time, a linear analytical formulation is presented, with the aim of providing a simple but useful tool in support of design, and especially to estimate the maximum lateral displacement/resistance for a given log-house wall when subjected to in-plane lateral forces. There, the intrinsic mechanical features of corner joints and related aspects are properly considered (i.e., static friction phenomena, as well as the presence of small gaps, etc.). The analytical model, in addition, takes advantage of the numerically predicted joint stiffness values, being dependent on several parameters. As shown, rather good agreement is obtained between the FE model output, the analytical predictions and past reference experimental/numerical results available in the literature for full-scale log-house walls under in-plane lateral loads, hence suggesting the potential of the proposed approach. In conclusion, possible Force-Preload-Displacement (FPD) charts are presented, to act as simplified tools for preliminary design considerations.
\end{abstract}

Keywords: log-house shear walls; lateral load resisting systems; Finite-Element (FE) numerical model; sensitivity study; analytical model; force-preload-displacement design charts

\section{Introduction}

In this paper, the structural response of timber log-house walls under in-plane lateral loads is investigated via Finite-Element (FE) numerical and analytical models. Log-house (or log-haus, Blockhaus, etc.) solutions represent a traditional construction system widely used in northern regions but also in urban regions with high seismic hazard such as the Mediterranean area. The constructive principle of log-house walls and three dimensional (3D) building assemblies is represented by the superposition of a series of timber logs. The basic timber components of each main wall interact with each other-and with the orthogonal logs-by simple mechanisms such as tongue-and-groove connections, corner 
joints and surface frictional contacts, while the use of mechanical connectors and fasteners, as well as adhesive connections, is reduced to a minimum. A key role, in this regard, is assigned to corner joints enabling the structural interaction between multiple walls, as a part of an overall assembly.

Within a full 3D building, each log-house wall has a primary load-bearing function, so as to transfer both vertical and lateral loads from the roof to the foundation systems. Further advantages of such a constructional solution are then represented by healthiness and good insulation properties, as well as by the fast assembly speed on the building site. Nowadays, the typical timber logs can be mostly rectangular-shaped or round-shaped, and realised in the form of solid timber or laminated beams. Although this traditional constructive system is relatively ancient in origin, the structural response under ordinary and extreme design loads is not well known yet, and no explicit provisions are given by standards in use (i.e., the Eurocodes 8 or 5 [1,2]) for the design of timber structures.

Only in the last decade, several research efforts have focused on the structural performance of log-house walls under different loading conditions of technical interest, including buckling-related aspects [3-7], fire endurance investigations [8], as well as the performance assessment of log-house systems under in-plane lateral loads $[9,10]$, or the effects of foundation anchorage systems on their actual behaviour [11]. In terms of seismic design, an experimental characterization of the monotonic/cyclic performance of corner joints under in-plane lateral loads has been proposed in References [12,13], together with a simplified rheological model for full-scale shear walls, while full-scale seismic analyses on single walls and/or 3D building assemblies are reported in References [14-16]. Recently, special attention has been paid at assessing the seismic performance of log-house systems equipped with additional metal stiffeners [17].

Following the past research investigations, this paper aims at further exploring the structural performance of log-house shear walls, with careful attention for the typical corner joints in use, when subjected to a combination of in-plane compressive loads (i.e., dead loads, etc.) and in-plane lateral loads (i.e., seismic events, wind pressure, etc.). While simplified analytical formulations are available to estimate the in-plane shear resistance of these joints, no specific provisions are given in the literature for their stiffness assessment (see for example References $[1,9,10]$, etc.). To this aim, a selection of past experimental tests on single corner joints is first briefly described in Section 2. Finite-Element numerical (FE) results from monotonic analyses carried out in ABAQUS [18] on "Standard" corner joints are then presented in Section 3, as obtained in accordance with past numerical efforts [17]. Their preliminary validation is carried out towards the past push-out/pull-out tests reported in [12,13]. Given the appropriate FE description of the actual loading and boundary conditions, as shown, the key aspects in the in-plane lateral response of these joints are represented by the mechanical interaction between the FE model components and by the input material and geometrical properties of the timber logs. As is known, the main contribution during the lateral loading-displacement phase of log-house systems is in fact represented by static friction phenomena, which typically occur before the interlocking contribution of each corner joint could be activated. There, however, the amplitude of small gaps between the intercepting logs (due to production tolerances or deriving from the assembly process) can have marked effects, when combined with additional uncertainties and/or variations in the compressive preload level, static friction coefficient, etc. (see References [9,12,13,15-17]). Major effects of material stiffness/resistance properties, preload amplitude, friction coefficient and loading protocol (with respect to the position of gaps) are hence briefly discussed in Section 3.3, based on parametric FE simulations.

The FE models are hence used in Section 3.4 to derive a reference value for the equivalent stiffness $K_{e l}$ of Standard joints under different loading configurations. The values are used for a simple but accurate analytical model, herein proposed for a preliminary design of log-house timber walls under in-plane lateral loads (see Section 4). The typical corner joint is considered to be an elastic extensional spring. At the same time, static friction contributions are evaluated by means of a classical Coulomb law, while the presence of possible gaps is properly considered in the lateral displacement evaluation. The accuracy of the analytical formulation is first assessed towards selected 
past full-scale experimental [12,13] and numerical [15] results of literature for full-scale log-house walls, while parametric analytical calculations are further developed and proposed in the form of possible Force-Preload-Displacement ("FPD") graphical charts in support of design.

\section{Past Experimental Studies on Log-House Corner Joints: Summary of Test Methods and Results}

Monotonic and cyclic tests were carried out in 2012, at University of Trento (Italy), on a set of small-scale specimens representative of the typical carpentry joint typologies in use for log-house structural systems. The series of tests was aimed at obtaining the load-displacement relationship, according to a common testing protocol, for different geometries of joints, both in compression (push-out) and in tension (pull-out), under an assigned compressive preload (see References [12,13]). The typical small-scale specimen, see Figure 1, was intended to be representative of a portion of log-house wall, and basically consisted of five timber logs, three logs belonging to the main wall (parallel to the in-plane lateral loading direction), and two of the orthogonal one, with C24 the resistance class of spruce according to EN338 [19]. Each timber component was characterized by a $b=90 \mathrm{~mm} \times h=160 \mathrm{~mm}$ nominal cross-section, with $500 \mathrm{~mm}$ the length (see Figures 1 and 2).

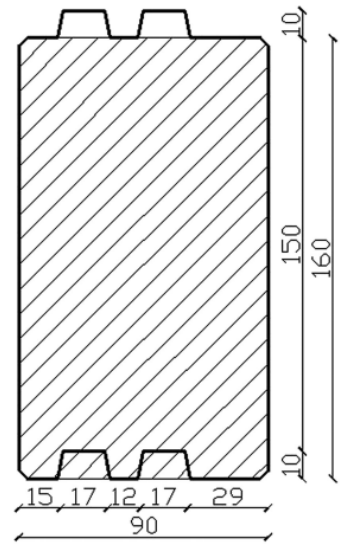

(a)

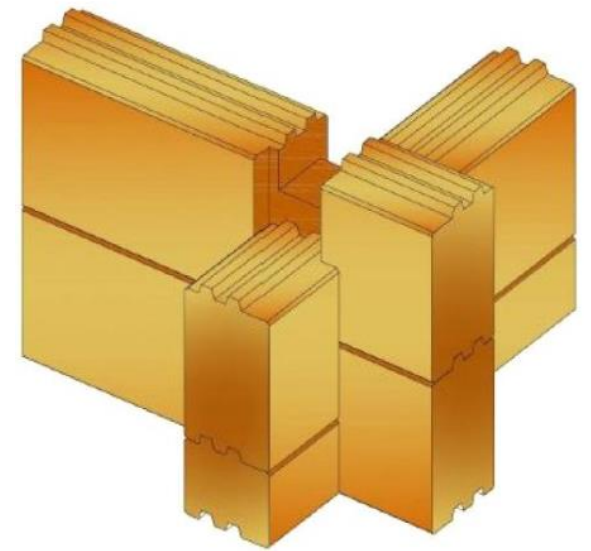

(b)

Figure 1. Reference timber log and joint (www.haus.rubner.com), with evidence of (a) cross-sectional geometry (nominal dimensions are given in $\mathrm{mm}$ ) and (b) Standard, saddle notch, corner joint specimen.

In order to reproduce the actual working condition of a log-house wall under in-plane compression (i.e., deriving from the sustained roof and/or inter-storey floors) and in-plane lateral loads (i.e., due to seismic events), a bespoke loading setup was developed (Figure 2), being inclusive of a L-shaped reaction frame and a vertical restraining system. The latter was connected to the reaction frame using two M16 threaded rods and steel springs (with $100 \mathrm{~N} / \mathrm{mm}$ their stiffness), to impose and keep the desired pre-compressive loads constant through the tests, but at the same time to allow possible (horizontal) sliding for the movable restraining member. Within the experimental program, a total initial tightening force/preload ( $P$, in the following) of $10 \mathrm{kN}$ or $5 \mathrm{kN}$ was in fact assigned to the rods, and kept fixed during the full experiments. The $P$ values were chosen to be representative of a uniform compressive load in the timber logs in the order of $10 \mathrm{kN} / \mathrm{m}$ and $5 \mathrm{kN} / \mathrm{m}$ respectively, and hence accounted for the typical compressive loading rate of full-scale log-walls belonging to two-storey residential buildings. Low-friction plates consisting of Polyzene foils [20] were finally interposed between the top/bottom logs and the steel setup. The in-plane lateral load was then imposed to the top $\log$ of each specimen, and a linear displacement transducer was fixed to the end section of all the timber members, to monitor their relative slip and rotation. 


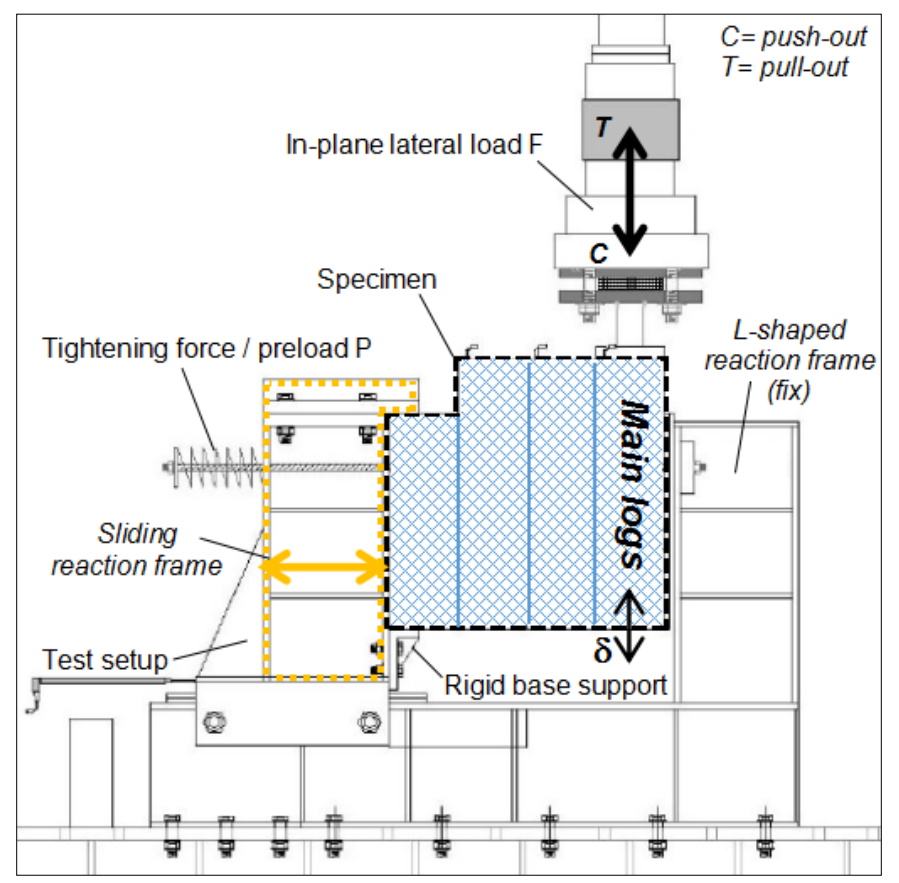

Figure 2. Schematic drawing of the testing apparatus (front view), in accordance with References [12,13].

Within the full experimental investigation reported in References [12,13], five monotonic (compressive (push-out) and tensile (pull-out)) tests, and one cyclic test were dedicated to the assessment of the structural efficiency of Standard corner joints according to Figure 1b. In this paper, the series of monotonic tests only are considered, for FE comparative purposes (see Section 3).

\section{Finite-Element Numerical Investigation}

\subsection{Model Assembly and Solving Approach}

Following and extending the experimental study in References [12,13], the FE numerical investigation on Standard joints was carried out in ABAQUS [18]. The typical FE model was assembled in accordance with Reference [17], where another set of small-scale samples from the past experimental campaign (i.e., small-scale timber log assemblies with steel rounded dovetails stiffeners) was in fact numerically explored. As such, the FE assembly consisted of few basic components (see Figure 3), to reproduce the timber logs, the test setup devices and the axial springs for the application of the initial pre-compressive.

According to References [9,17], 3D solid elements (8-node, C3D8R type) were used for all the FE parts. Mesh pattern and size were then set to maximize the computational efficiency of FE models, but preserve the accuracy of predictions, especially in the regions of contact between the timber log notches. Each timber log was then described with a simplified, regular $b \times h$ cross-section, deprived of the characteristic small protrusions and tongues along the top and bottom surfaces (i.e., Figure 1a). Given the nominal dimensions of timber logs, a nominal gap $t_{\text {gap }}=1 \mathrm{~mm}$ was also numerically taken into account for the longitudinal members subjected to the imposed in-plane lateral loads, at their interface with the orthogonal members (Figure 3). The estimated average value was assumed-due to the lack of detailed measurements from the past experimental programme-to be well representative of the typical tolerance gap due to production requirements (see also References $[9,13,17]$ ). 


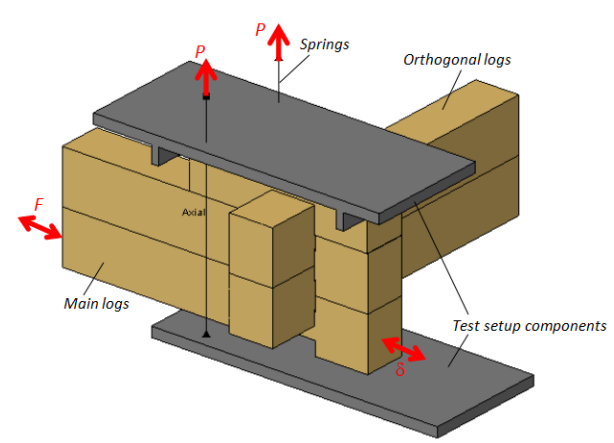

(a)

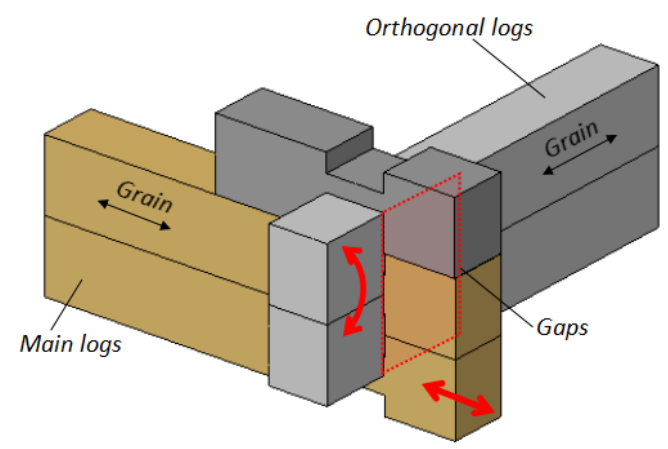

(b)

Figure 3. FE modelling of a Standard joint specimen (ABAQUS): (a) assembly view and (b) mechanical model.

A key role was finally assigned to contact interactions, so that the actual performance of such specimens could be properly estimated. Surface-to-surface "general contact" interactions were implemented at the interface of all the adjacent FE components. The typical interaction mechanism was implemented taking into account the possible overlap between timber logs. For all the surface contact algorithms, a general penalty approach was used, with minor variations in the basic input parameters associated to relative sliding only. For the timber-to-timber interfaces, a static friction coefficient $\mu=0.5$ was used [9,17], while $\mu=0.2$ was accounted in the presence of the Polyzene foils $[17,21]$. In the direction perpendicular to all the involved surfaces, the hard normal behaviour was also used, so that compressive stresses could be transferred among two FE model components in contact (as far as any kind of damage in materials occurs) and compenetration could be avoided. Such a FE assumption proved to have major effects, based on the intrinsic features of the explored samples, in the region of internal joint notches, where the main and orthogonal logs first interact under the assigned loading and boundary conditions. Possible detachment of the involved timber log surfaces, when subjected to null compressive pressures, was also taken into account, so that the influence of partial uplift and overturning of both the main and the orthogonal logs could be considered on the overall in-plane response for the examined specimens.

The typical simulation was hence carried out in the form of a dynamic analysis (ABAQUS/Explicit), with quasi-static application of the imposed external loads, consisting of two sub-steps. First, the initial compressive load was imposed to the specimen (i.e., axial rods). At this stage, only minor adjustments of the timber logs within the test setup were expected. On the so pre-loaded FE model, a monotonic analysis (with linear increase of the imposed in-plane shear load for the top specimen log) was hence carried out. Based on the experimental results for the specimens object of analysis, the typical numerical simulation was manually stopped as far as (i) the maximum lateral force or (ii) the ultimate displacement achieved in the past monotonic tests was first achieved.

Concerning the mechanical characterization of C24-class spruce, an elasto-plastic, orthotropic constitutive law representative of the mean mechanical features of structural timber members with defects was initially considered. As a Modulus of Elasticity (MOE) in the direction parallel to grain, the mean value $E_{0, \text { mean }}=11,000 \mathrm{MPa}$ recommended by EN338 [19] was taken into account, while for the MOE in the direction perpendicular to grain and for the shear modulus the nominal values $E_{90, \text { mean }}=370 \mathrm{MPa}$ and $G_{\text {mean }}=690 \mathrm{MPa}$ were used, respectively.

Possible failure mechanisms in the contact regions of logs were also considered, to assess the in-plane lateral response of Standard joints as a function of crushing and local plasticization phenomena, due to compression of logs (see also Reference [17]). Given the actual loading and boundary configuration (Figure 3b), major sensitivity to the input damage parameters was expected for the orthogonal logs, in the contact regions of the joint notches, where the overall load-bearing capacity is respectively governed by the compressive resistance of logs in the direction perpendicular 
to the grain $\left(f_{c, 90}\right.$, for the orthogonal members) and in the direction parallel to the grain $\left(f_{c, 0}\right.$, for the main logs). An elasto-plastic, Von Mises stress-strain relationship was defined for the timber members, with a limit mean value for such a compressive strength set equal to $f_{c, 90} \approx f_{c, 90, k} / 0.85=2.94 \mathrm{MPa}$, where $f_{c, 90, k}=2.5 \mathrm{MPa}$ [19]. Given a characteristic resistance $f_{k}$, the corresponding $f_{m}$ value was in fact calculated as [22]:

$$
f_{m}=\frac{f_{k}}{\left(1-1.645 \cdot \operatorname{COV}\left[f_{m}\right]\right)}
$$

with:

$$
\operatorname{COV}\left[f_{m}\right]=10 \%
$$

Local material orientation systems were defined for orthogonal and longitudinal logs. To account for timber anisotropy, the Hill criterion (with isotropic hardening) was also implemented. Based on the material orientation and the reference $f_{c, 90}$ resistance value, the corresponding anisotropic stress ratios were properly calculated for the other principal directions of interest, by accounting for the nominal mechanical features of C24-class spruce [17,19]. Following Equation (1), the FE assembly was hence calibrated to account for possible damage mechanisms due to (i) compression perpendicular to the grain $\left(f_{c, 90}=2.94 \mathrm{MPa}\right)$, (ii) compression parallel to grain $\left(f_{c, 0}=24.70 \mathrm{MPa}\right)$ and (iii) shear $\left(f_{v}=2.82 \mathrm{MPa}\right)$.

\subsection{Validation of FE Models towards the Past Experiments}

Generally, a rather interesting agreement was observed by comparing the predictions of the typical FE model described in Section 3.1 ("FE-STRU", in the following) and the corresponding test data $[12,13]$, in terms of overall performance and qualitative local phenomena. Figure 4 presents the obtained results, in the form of in-plane lateral load $F$ versus lateral displacement $\delta$ of the top log, for both the preload conditions ( $P=10 \mathrm{kN}$ and $5 \mathrm{kN})$.

The reference FE models, as shown, offer reliable estimations for the actual elastic stiffness $K_{e l}$ and maximum resistance $F_{\max }$ of the examined small-scale specimens, compared to the experimental estimations. Minor scatter can be noticed in the plotted curves, as the effect of several aspects such as the geometrical simplifications in the FE description of test setup, as well as of the specimens' components. It was shown in Reference [9] via quasi-static friction experiments on small assemblies that typical grooves and tongues along the base/top faces of the overlapping logs, for example, can affect the actual sliding of timber members. A key role is then assigned to the presence of possible small gaps at the interface between the main/orthogonal logs.

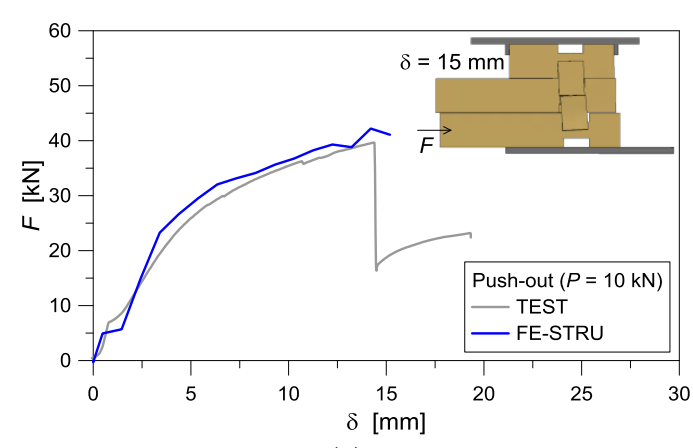

(a)

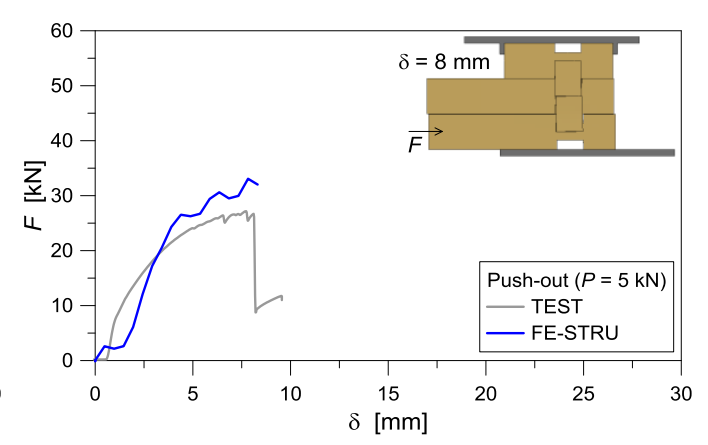

(b)

Figure 4. Load-displacement response of Standard joints, as obtained experimentally $[12,13]$ and numerically (ABAQUS), under an assigned preload $P$ of (a) $10 \mathrm{kN}$ and (b) $5 \mathrm{kN}$.

In Figures 5 and 6, selected contour plots are proposed for the FE-STRU assembly $(P=10 \mathrm{kN})$ at an imposed displacement of $5 \mathrm{~mm}$ and $15 \mathrm{~mm}$ respectively. The progressive crushing phenomena in the internal notches of the orthogonal log can be perceived (compression perpendicular to the grain), 
with additional effects due to compressive stresses parallel to the grain (for the longitudinal logs). Interestingly, for lateral displacements even larger than $5 \mathrm{~mm}$ (Figure 5), limited compressive and shear stresses were numerically estimated, with a mostly elastic response of the joint.

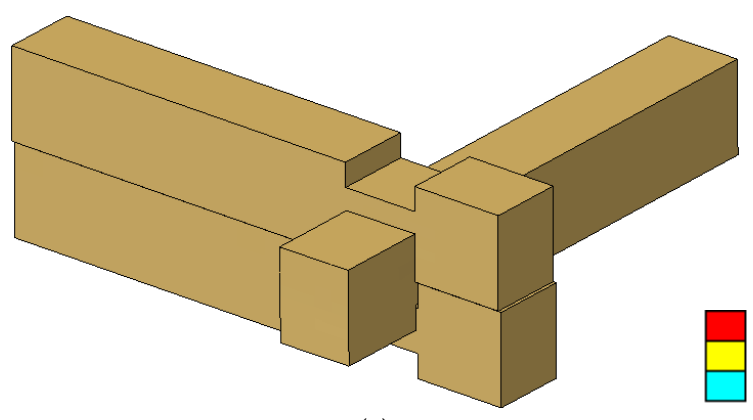

(a)

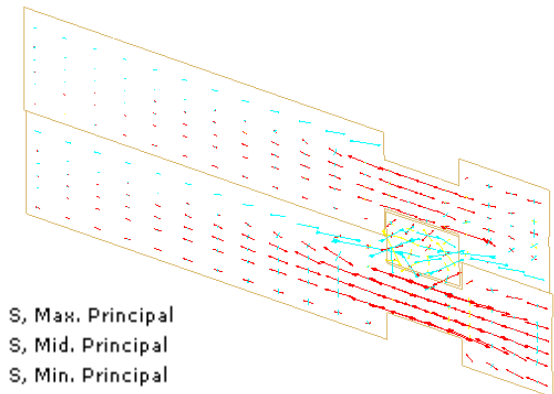

(b)
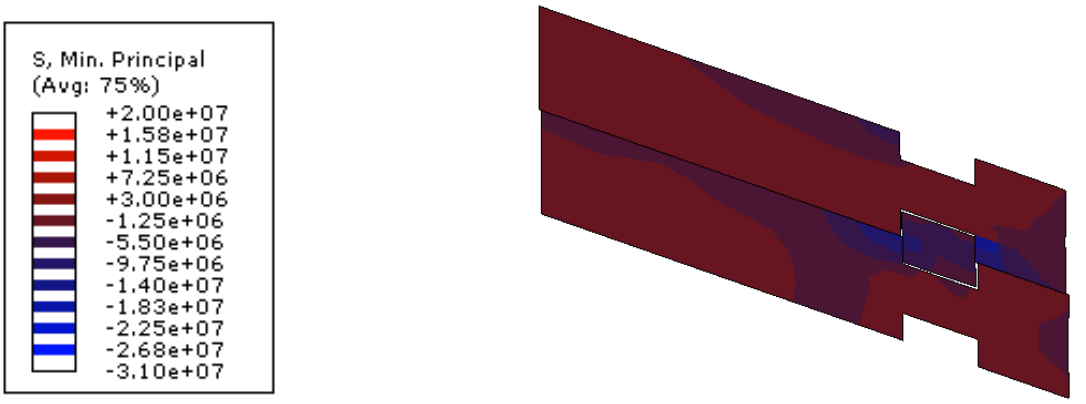

(c)

Figure 5. Standard joint under in-plane lateral loads (push-out, $P=10 \mathrm{kN}$ ), at an imposed displacement $\delta=5 \mathrm{~mm}$ (ABAQUS, FE-STRU). (a) Deformed shape, with (b) distribution of principal stresses (vectorial representation) and (c) contour plot of compressive stresses (legend in $\mathrm{Pa}$ ).

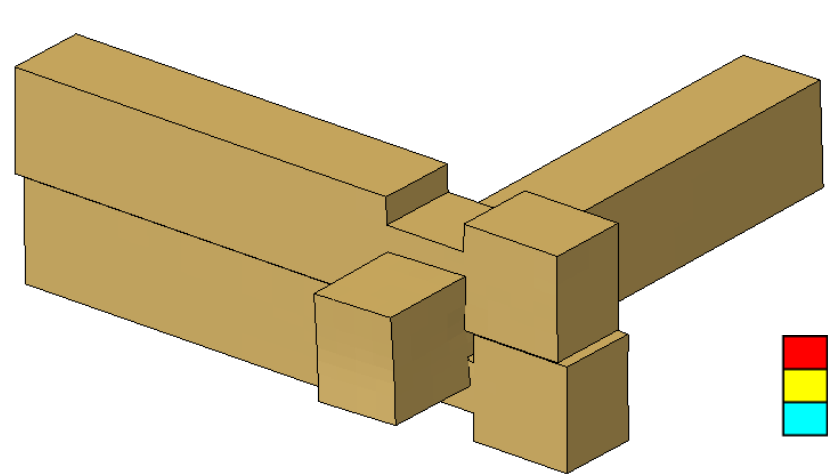

(a)

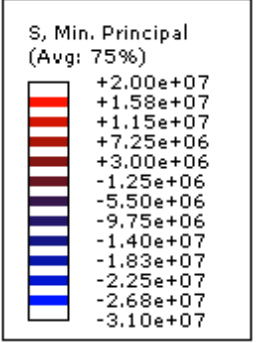

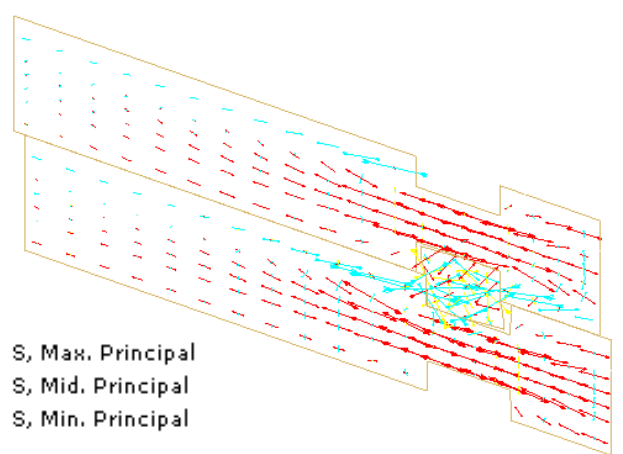

(b)

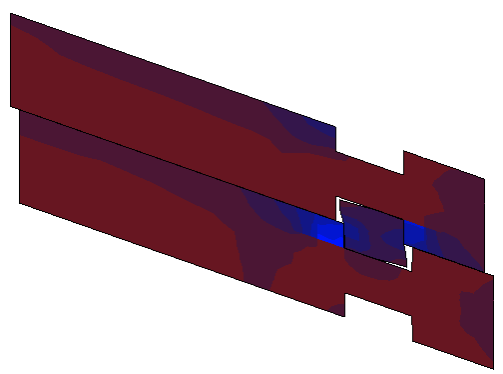

(c)

Figure 6. Standard joint under in-plane lateral loads (push-out, $P=10 \mathrm{kN}$ ), at an imposed displacement $\delta=15 \mathrm{~mm}$ (ABAQUS, FE-STRU). (a) Deformed shape, with (b) distribution of principal stresses (vectorial representation) and (c) contour plot of compressive stresses (legend in $\mathrm{Pa}$ ). 


\subsection{Discussion of Push-Out Parametric FE Results and Influencing Parameters}

Based on the FE outcomes summarized in Figures 4-6, a short parametric study was carried out on the same numerical models, to assess the effects of the $F-\delta$ estimations of some key input parameters: the sensitivity of FE models to material properties, tightening/preload, friction coefficient, and loading configuration (with respect to the gap position). Comparative results are summarized in the following sections, for all the parametric models, and discussed with reference to the FE-STRU model (Section 3.1), as well as past experimental findings [12,13].

\subsubsection{Timber Properties}

The effect of input material properties was first investigated, see Table 1, based on literature findings for C24 spruce mechanical features $[19,23]$ and experimental results available for small-scale log-house components [7]. In Table 1, the FE-STRU material features refer to the mean input mechanical properties provided in Reference [19] for structural members without defects. Through the FE parametric study, the typical elasto-plastic constitutive law of timber was still described as in Section 3.1 for the FE-STRU assembly, but the reference input values for the mean strengths and/or moduli of interest were modified to account for:

- an ideal, orthotropic, linear elastic behaviour (FE-EL);

- an orthotropic, elasto-plastic material with resistance parameters available in the literature for small-scale timber specimens without defects (FE-noDEF, with average values provided in Reference [23]);

- an orthotropic, elasto-plastic material with stiffness and resistance properties experimentally derived from small-scale log-house components (FE-EXP, see Reference [7]).

Table 1. Key input mechanical properties (mean values) for timber (ABAQUS). Key: $\left(^{*}\right)=$ value taken from Reference [19]; $\left.{ }^{* *}\right)=E_{0, \text { mean }} / 16$ [24].

\begin{tabular}{cccccc}
\hline \multirow{2}{*}{ Parameter } & \multicolumn{4}{c}{ FE Model } \\
\cline { 3 - 6 } & & FE-STRU [19] & FE-EL & FE-noDEF [23] & FE-EXP [7] \\
\hline$E_{0, \text { mean }}$ & $\mathrm{MPa}$ & 11,000 & 11,000 & 13,000 & 11,556 \\
$E_{90, \text { mean }}$ & $\mathrm{MPa}$ & 370 & 370 & 450 & 192 \\
$G$ & $\mathrm{MPa}$ & 690 & 690 & $812^{* *}$ & 617 \\
$f_{c, 90}$ & $\mathrm{MPa}$ & 2.94 & - & 3 & 3.39 \\
$f_{c, 0}$ & $\mathrm{MPa}$ & 24.70 & - & 45 & 33.59 \\
$f_{v}$ & $\mathrm{MPa}$ & 2.82 & - & $2.82 *$ & $2.82^{*}$ \\
\hline
\end{tabular}

Figure 7a reports the parametric FE results. As expected, marked variations in the load-displacement curves can be noticed as far as the mechanical characterization of timber changes from the idealised, linear elastic assumption (FE-EL) to an elasto-plastic constitutive law, hence confirming the crucial role of crushing mechanisms for the overall performance assessment of the examined joints. Minimum variations can indeed be observed, from the same comparative plots, when assuming for the wooden members the mechanical features of structural timber with defects (FE-STRU), rather than the nominal values of small-scale specimens without defects (FE-noDEF), or the experimental values for small-scale log-house components (FE-EXP).

\subsubsection{Preload and Friction Coefficient}

Given the testing conditions assessed in Figure 4 ( $P=10 \mathrm{kN}$ or $5 \mathrm{kN}$ for push-out experiments), variations in the input properties of the FE-STRU reference assembly were then implemented in terms of preload amplitude. In Figure 7b, selected comparisons are proposed for $P$ values spanning from $5 \mathrm{kN}$ to $20 \mathrm{kN}(7 \mathrm{kN}, 10 \mathrm{kN}, 15 \mathrm{kN}$ the intermediate steps). As shown, compressive loads up to $P=10 \mathrm{kN}$ 
generally resulted in minor effects for the numerically predicted $F-\delta$ curves, as it is possible to perceive especially in the initial loading phases, where an adjustment of timber logs within the test setup components occurs. High compressive loads ( $P=15 \mathrm{kN}$ or $20 \mathrm{kN}$, in this study), otherwise, typically resulted in a partial increase of the maximum resistance $F_{\max }$, due to the beneficial effect of tightening, and its relation with friction phenomena. This is in line with past research studies for log-house systems under several design load conditions (see for example $[9,12,13])$. For the range of compressive loads of interest for Standard joints belonging to one to two-storey buildings, it is possible to notice in Figure $7 \mathrm{~b}$ a limited sensitivity of stiffness $K_{e l}$ and resistance $F_{\max }$ for the examined specimens.

Minor effects on the overall $F-\delta$ of the same FE assemblies were found to derive also from variations in the reference value for the static friction coefficient, for a given preload. In Figure 7c $(P=10 \mathrm{kN})$, numerical comparisons are proposed for $\mu=0.33$ [13] and $\mu=0.65$ [8], as experimentally derived from log-house full-scale assemblies and small-scale frictional specimens, respectively. The latter condition, in particular, was experimentally calculated from a series of small-scale log-house samples as the maximum frictional value ( $\mu=0.5$ the average of tests). In that case, such a friction coefficient was affected by tongues and grooves along the sliding surfaces of logs, hence resulting in a relatively high coefficient for timber-to-timber applications.

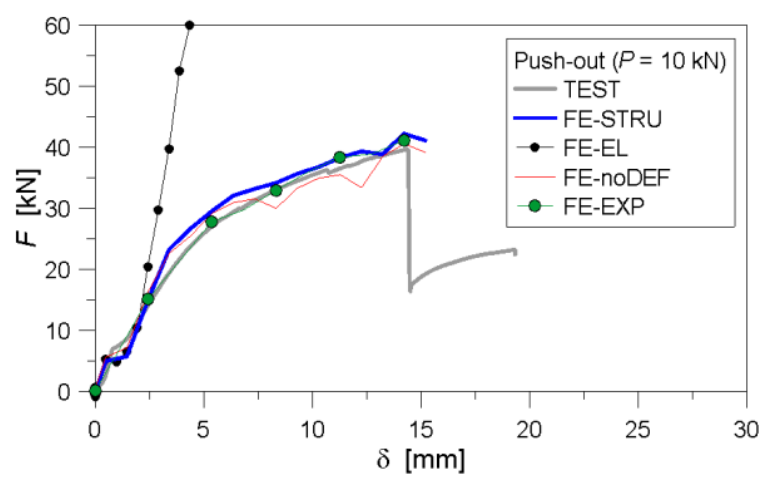

(a)

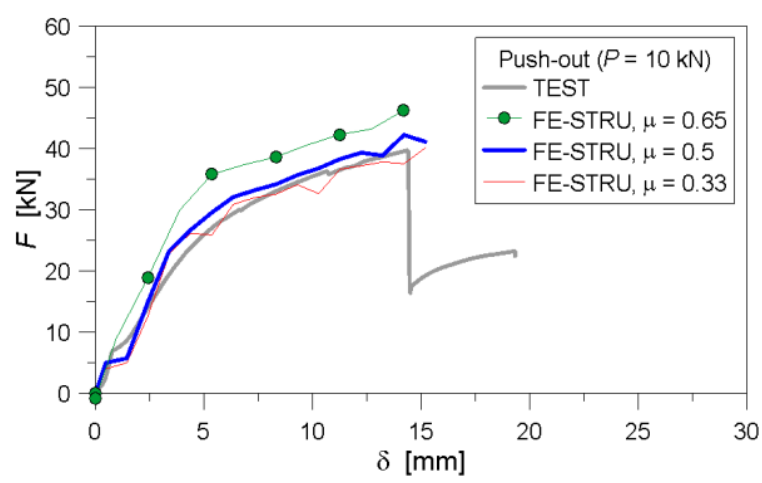

(c)

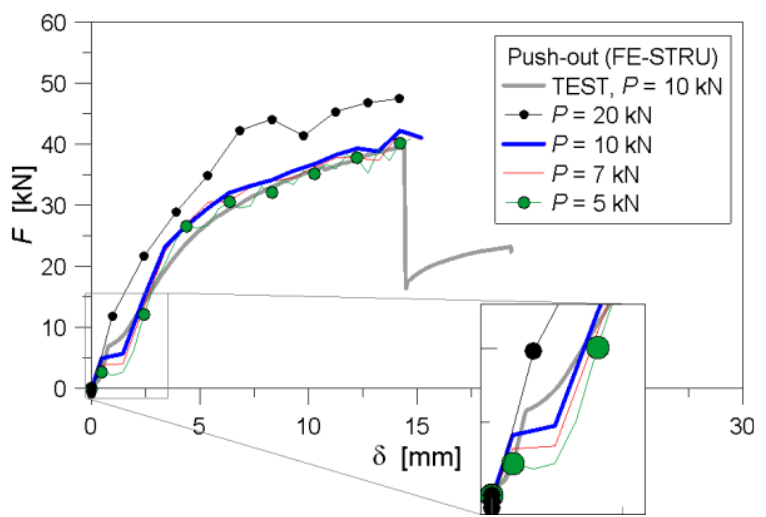

(b)

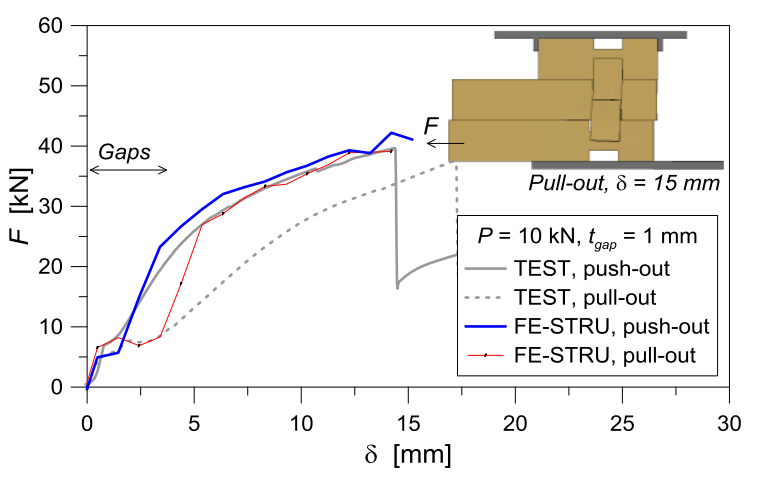

(d)

Figure 7. Load-displacement results for Standard joints, as obtained by changing (a) timber mechanical properties, (b) tightening level, (c) friction coefficient, and (d) loading configuration, with respect to the tolerance gaps (ABAQUS).

\subsubsection{Loading Configuration and Gaps}

At the final stage of the parametric FE study, the effects on the FE-STRU assembly due to the imposed loading configuration were also numerically investigated, to account for the possible sensitivity of the $F-\delta$ predictions to the presence of small gaps at the interface of logs when subjected to 
push-out or pull-out loading conditions. The results are given in Figure $7 \mathrm{~d}$, and compared with the corresponding test data. Given a nominal amplitude $t_{\text {gap }}=1 \mathrm{~mm}$, for the reference FE models, a shift can be clearly perceived in the load-displacement response of the pull-out sample, compared to the push-out system. Such an effect is in line with past experimental observations [12,13], where a marked sensitivity to gaps was perceived, with respect to the FE models. Such a scatter between experiments and numerical analyses can be reasonably justified by the actual amplitude of gaps (typically spanning from $0.5 \mathrm{~mm}$ up to $2 \mathrm{~mm}$ or $2.5 \mathrm{~mm}$, see also References [25,26]). As far as the gaps are closed and the principal logs are in contact with the orthogonal members, the joint activates and a mostly constant stiffness/ultimate resistance can be observed for both the loading configurations. In addition, it is important to highlight that the test specimens of Figure 2 were also partly affected by minor dead load effects (i.e., gaps and self-weight of logs).

\subsection{FE Derivation of the Corner Joint Stiffness}

A key role of refined 3D numerical models, as known, is the possibility to support and further extend the experimental observations, to address possible local phenomena or critical aspects in the typical response of a given structural system. On the other hand, advanced FE models can be modelling and computationally time consuming, or require computer software packages that are not suitable for daily design applications. In this context, simple analytical models and practical formulations can represent a robust and valid tool.

In Reference [9], for example, it was shown that the ultimate in-plane shear resistance $V_{\text {shear }}=F_{\max }$ of Standard joints according to Figure $1 \mathrm{~b}$ can be roughly predicted with the formulation currently given by the Eurocode 5 [2], as the weakest between compressive and shear resisting mechanisms. For the FE-STRU assembly object of investigation, for example, a mean shear resistance $V_{\text {shear }}=39.5 \mathrm{kN}$ can be expected, and this is in line with the experimental/ numerical results of Figure 7. No formulations are provided, however, to estimate the expected stiffness for the same joints. In addition, given a full-scale log-house wall with $n$ overlapping joints, limited load-displacements are expected in each one of them under the effects of an in-plane shear load. In other words, the ultimate configuration (i.e., resistance and displacement) for a single joint will be hardly achieved in a full-scale building.

In this research study, given the FE parametric analyses partly discussed in Section 3.3, the numerical results were hence used to assess the sensitivity of FE analysis to various influencing parameters of interest for log-house corner joints, towards the development of an analytical model for log-house walls under in-plane seismic loads. The same FE analyses, in particular, were used for a first estimation of the reference stiffness $K_{e l}$ for the typical Standard joint stiffness, being this parameter dependent on the preloading condition and on the imposed lateral force.

Following Section 3.3, for design purposes, the FE-STRU numerical load-displacement curves can be roughly approximated by a straight line with constant slope, so to account for the relevant stiffness $K_{e l}$ of each joint. In Figure 8, for example, estimations for the joint stiffness were carried out for the push-out specimen with $P=10 \mathrm{kN}$, based on Reference [27]. The $K_{e l}$ value for the Standard joint under monotonic loading, in particular, was derived in accordance with the EN 12512:2001/ A1 [28] and EN 26891 [29] provisions. In the $F-\delta$ curve of Figure 8 , the maximum load-bearing capacity (peak strength) of the specimen is denoted with $F_{\max }$, while $\delta_{\max }$ is the conventional limit displacement $(15 \mathrm{~mm})$. The ultimate configuration for a given joint, in general should be detected as the earliest achievement of $F_{\max }$ and $\delta_{\max }$. In Figure 8, the elastic slip modulus to account for mechanical performance assessments is hence derived as the slope of the line connecting the $F-\delta$ curve points corresponding to $10 \%$ and $40 \% F_{\max }$. For comparative purposes, the so parametrically estimated stiffness values are reported in Table 2 and Figure 9. 


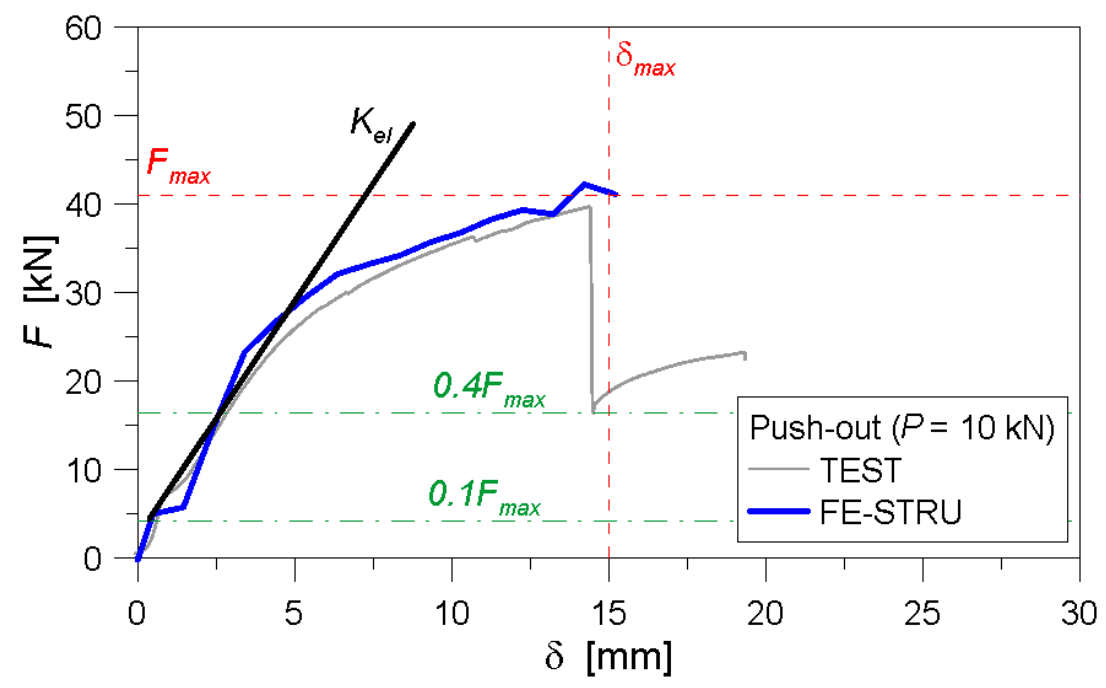

Figure 8. Estimation of the $K_{e l}$ stiffness for Standard joints under in-plane lateral loads, based on numerical (ABAQUS) load-displacement curves. Example for the FE-STRU push-out specimen.

Table 2. Derivation of the $K_{e l}[\mathrm{kN} / \mathrm{m}]$ for standard joints, according to Figure $8(P=10 \mathrm{kN})$, for different material properties.

\begin{tabular}{cccc}
\hline \multicolumn{4}{c}{ Reference Configuration } \\
\hline TEST & FE-STRU & FE-noDEF & FE-EXP \\
\hline 5471 & 5195 & 5306 & 5062 \\
\hline
\end{tabular}

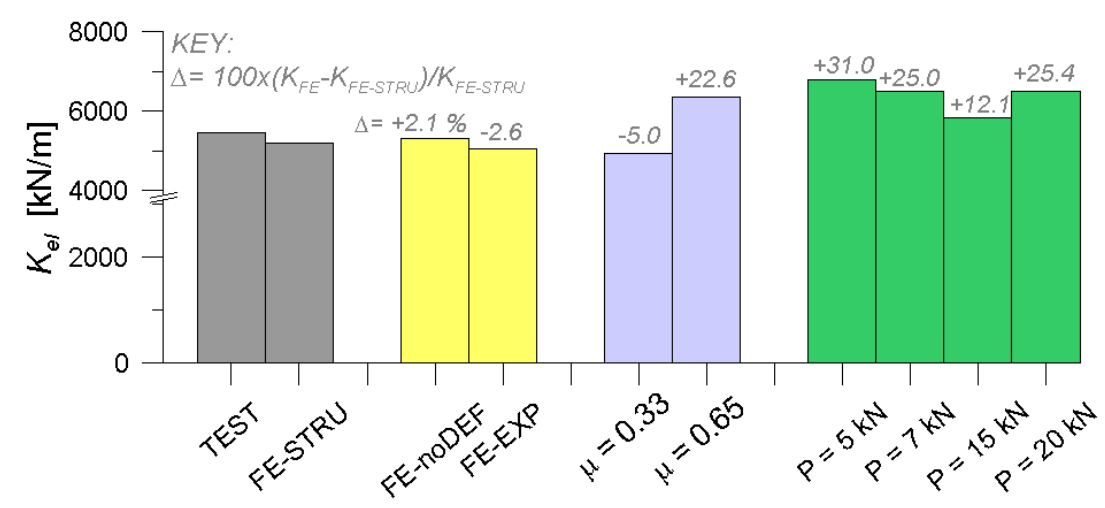

Figure 9. Variation of the $K_{e l}$ stiffness for Standard joints, as a function of friction coefficient and preload (ABAQUS).

As also highlighted in Figures 7 and 8, the typical $F-\delta$ response of the examined joints has approximately a linear trend for the first loading phase, i.e., for lateral loads up to $\approx 25 \mathrm{kN}$. Such a load amplitude corresponds-for most of the loading conditions herein investigated-to an average displacement of 4-5 mm, typically coinciding with a fully elastic response of the timber members (or minor compressive damage, see Figure 5). As far as $n$ overlapping joints are used within a full-scale wall assembly (with $n=16-17$ for a one-storey building and $H=2.8 \mathrm{~m}$ ), this means that lateral deflections even larger than $\approx 80 \mathrm{~mm}$ can be achieved (i.e., $\geq 3 \%$ the inter-storey drift) before local damage could severely manifest in the corner joints. For preliminary design assessments, reliable calculations could be hence carried out, as far as the joint stiffness is known. 
The variation of stiffness values collected in Figure 9, in this regard, suggests a certain sensitivity especially to static friction phenomena (as also expected, due to the intrinsic features of the examined samples). At the same time, it is possible to see how $K_{e l}$ modifies with the initial preload level, compared to the FE-STRU assembly, being responsible of more pronounced or weak frictional phenomena, and combined uplift/overturning of logs. For high preload amplitudes ( $P=15 \mathrm{kN}$ or $20 \mathrm{kN}$, in Figure 9), the corner joint can take advantage of added tightening contributions, hence resulting in a progressive increase of $K_{e l}$. The numerically estimated $K_{e l}$ values for low compressive levels $(P=5 \mathrm{kN}$ or $7 \mathrm{kN})$ tend also to increase, compared to the FE-STRU configuration. Such a counter-intuitive result is strictly related to the adjustment of logs with the test setup, for the initial loading phase $(F<5 \mathrm{kN})$, as also emphasised by the parametric plots of Figure $7 \mathrm{~b}$. In this context, it can be further pointed out that the derivation of the key mechanical parameters for the examined joint typology can be highly affected by a multitude of aspects, hence requiring specific studies.

\section{Simplified Analytical Model for the Design of In-Plane Loaded Log-House Walls}

A simple analytical formulation that accounts for the key mechanisms involved in the in-plane displacement evaluation of log-house systems was finally developed.

For seismic design purposes, a rational estimation of the actual load-bearing performance and deformation capacity of log-house systems should properly take into account the intrinsic flexibility of the structural typology. According to the existing design standard provisions, see for example the FEMA 356 document [30], the ultimate inter-storey drift $\delta_{\max }$ at the Collapse Limit State should not exceed-for wooden walls-the limit value of $3 \%$. Such a limit condition is typically expected to occur together with severe damage of the primary and secondary timber components (i.e., "connection loose, nails partially withdrawn; some splitting of members and panels; veneers dislodged"). It was shown in References $[12,13,15-17]$ that log-house systems are typically able to achieve large deformations before damage in the carpentry joints, as a major effect of sliding mechanisms that need to be fulfilled before the joints themselves could provide their active mechanical contribution. To this aim, an analytical model was proposed in Reference [13], to estimate the in-plane lateral performance of log-house walls by accounting for a single, equivalent spring representative of the overall effect of $n$ corner joints. In doing so, several values of joint stiffnesses were calibrated to reproduce the typical joint behaviours discussed in Section 3. In References [15,16], a numerical investigation was then presented for single walls or full 3D log-house buildings under seismic records. There, each corner joint was mechanically described in the form of springs, where the input load-displacement response for each one of them was derived from cyclic tests partly summarized in Section 2. In most of the past studies, according to Figure 8 , it was highlighted that large wall/building lateral deformations due to seismic loads are typically associated with limited deformations in each corner joint, being the overall structural response of a given log-house systems strictly related to a sequence of progressive/small sliding mechanisms at the level of the log interceptions. In this regard, the analytical model herein proposed still accounts for a set of geometrical and mechanical simplifications for the description of the real mechanical problem. However, the initial load-displacement phase of the typical corner joints is taken into account (see Section 4.1).

\subsection{Basic Assumptions}

In Figure 10, the typical $L \times H$ log-house shear wall is represented, together with its corresponding mathematical model. Such a log-house model is obtained by the superposition of $n \operatorname{logs}$ in contact along their top-bottom surfaces, and a sill log joined at the foundation level. At this stage, the foundation restraints are assumed to be indefinitely rigid for the base logs. The longitudinal logs interact then with the orthogonal members by means of corner joints according to Figure 1 . The main log-haus wall is then uniformly pre-compressed by a distributed load $(p)$ and subjected to an in-plane lateral load $(F)$.

Under the assigned load $F$, the expected top log displacement can be assumed as the result of sequential relative displacements of logs, as well as of local mechanical behaviours (initial crushing in 
the region of notches, etc.), due to the progressive activation of the corner joints. The analytical model of Figure 10b, in particular, assumes that:

- the corner joints are represented in the form of linear elastic springs, with equivalent stiffness $K_{e l}$ (see Table 2 and Figure 9);

- $\quad$ static friction effects are accounted, at the level of each log, in the form of $f_{i}$ Coulomb forces, with $i$ $=1, \ldots n-1$;

- the presence of $n$ tolerance gaps in the region of corner joints is also considered, as an additional contribution for the total displacement estimation. At this stage, given the structural system of Figure 10, the carpentry joints are considered at the logs ends only (i.e., possible internal joints and restraints are disregarded).

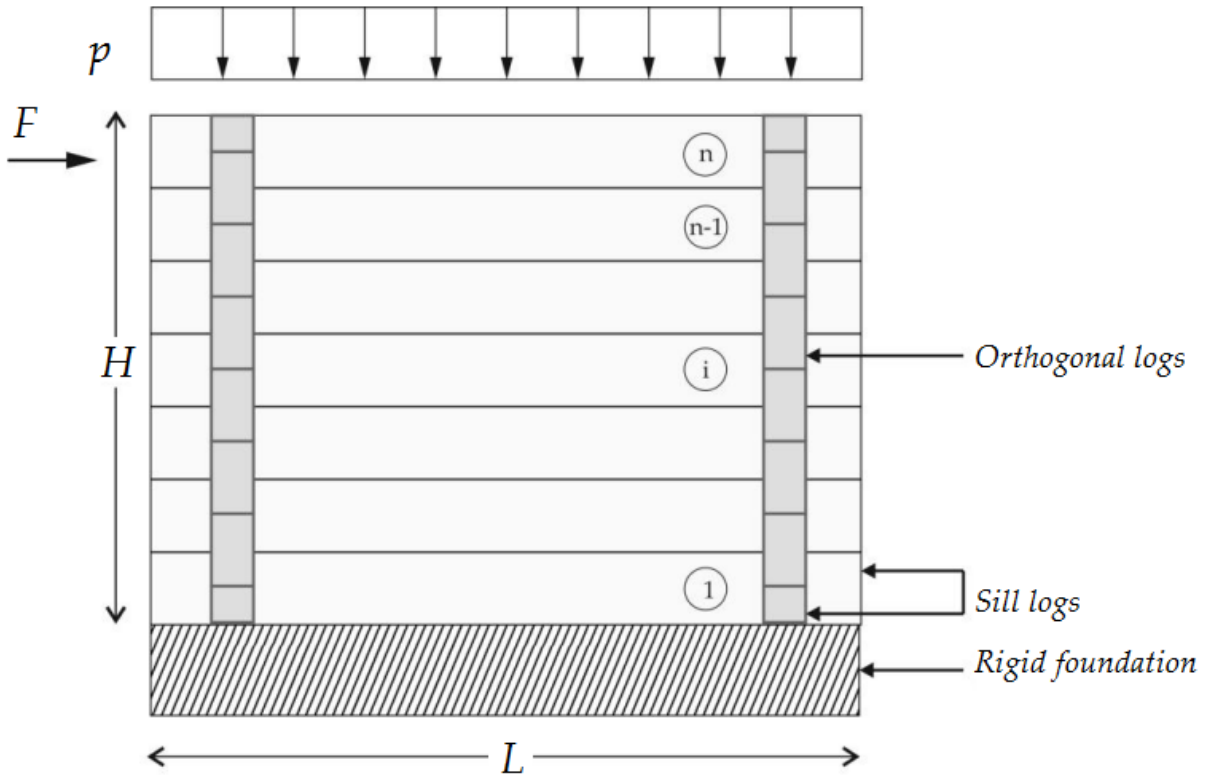

(a)

$p$
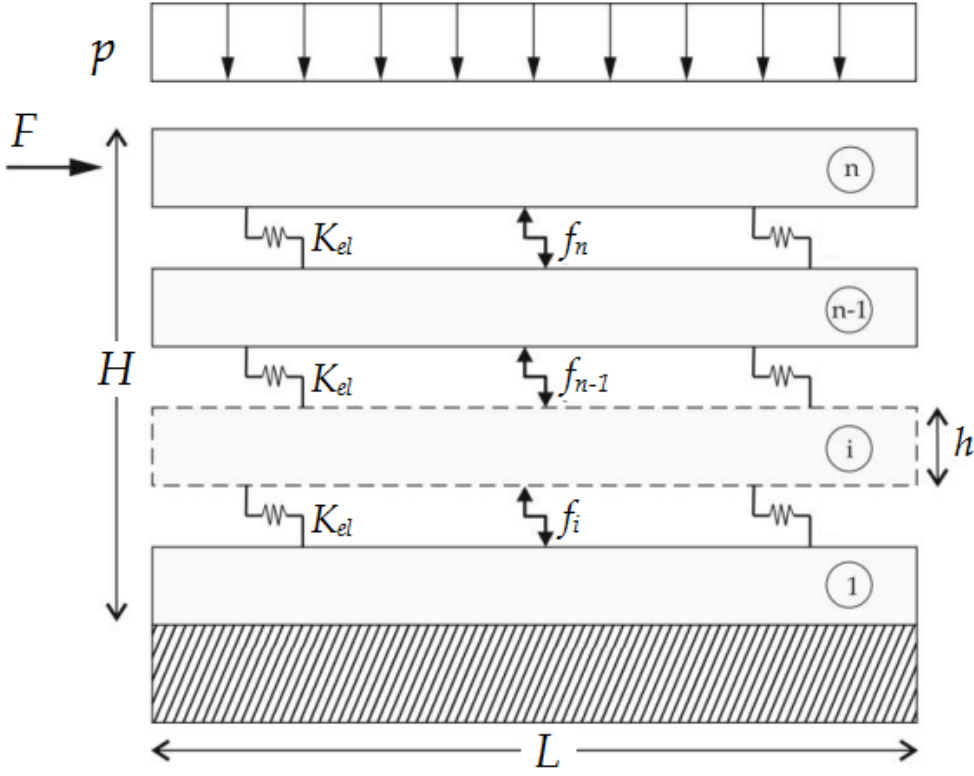

(b)

Figure 10. Log-house shear wall under combined in-plane compression and lateral loads: (a) reference full-scale assembly (front view) and (b) corresponding analytical model. 
According to Figure 10b, the static friction contribution at the level of each log, in particular, is conventionally defined as:

$$
f_{i}=\mu \cdot\{[(n-1)+1] \cdot m g+p L\}
$$

where $\mu$ is the static friction coefficient previously defined, $p$ the distributed in-plane compression, while $m g$ is the self-weight of timber $\operatorname{logs}$ and $i=2, \ldots n$. The force equilibrium condition requires, for each $i$-th $\log$, that:

$$
F=f_{i}+n_{j, l o g} K_{e l} \delta_{i}
$$

where $n_{j, l o g}=2$ are the lateral joints and hence:

$$
\delta_{i}=\frac{F+f_{i}}{2 K_{e l}}
$$

In Equations (3) and (4), finally, $K_{e l}$ is the stiffness value for the joint type/loading condition of interest (see Section 3.4). Obviously, the slip condition:

$$
F>f_{i}
$$

must be satisfied, to activate the relative sliding of each log, and hence the full log-house wall lateral deformation. Otherwise, partial slip mechanisms could also arise.

The total lateral displacement of the wall must be estimated by considering the presence of possible initial gaps, resulting in a total lateral deformation equal to:

$$
\delta_{\text {top }}=\sum_{i=2}^{n} \delta_{i}+n \cdot t_{g a p}
$$

\subsection{Validation of the Analytical Model}

The analytical formulation herein presented is first validated by load-displacement comparisons with the experimental monotonic and cyclic test results originally discussed in References $[12,13]$ for full-scale log-house shear walls, and partly numerically investigated in Reference [15]. To this aim, the $L=4.20 \mathrm{~m}$ wide ( $3.91 \mathrm{~m}$ the span of outriggers) $\times H=2.8 \mathrm{~m}$ tall wall composed of a set of C24-class timber elements ( $b=90 \mathrm{~mm} \times h=160 \mathrm{~mm}$ their cross-section, see Figure 1a), under a lateral load $F$ and a total pre-compressive load of $10 \mathrm{kN} / \mathrm{m}$ was selected from the past investigation and taken into account for the analytical estimations ("M_ST_90" sample, according to Reference [13]). Following Equations (3)-(7), the input data $\mu=0.33[12,13]$ and $t_{g a p}=1 \mathrm{~mm}$ (or $2 \mathrm{~mm}$ ) were also considered. In terms of connection stiffness, finally, the FE numerical value $K_{e l}$ reported in Table 2 for the adopted joints was used $(P=10 \mathrm{kN})$.

The comparative results are shown in Figure 11, as obtained from cyclic loading conditions (see Figure 11a), or by changing some input parameters for the analytical model (Figure 11b). The past experiment was stopped at the attainment of a maximum top load of $\approx 90 \mathrm{~mm}$, corresponding to a lateral load $F_{\max } \approx 42 \mathrm{kN}$. Accordingly, for the analytical calculations, the same maximum value for the imposed lateral load was taken into account. Figure 11a shows a rather close correlation between experimental, numerical and analytical predictions for the investigated full-scale sample, hence suggesting the validity of the mathematical model herein proposed.

In Figure 11b, additional analytical calculations are shown for the same full-scale assembly, together with the corresponding experimental curve (monotonic test from Reference [13]). There, the reference ultimate inter-storey drift recommended in Reference [30] for wooded load-bearing vertical systems is also emphasized. In terms of both experimental and analytical response, the actual role of tolerance gaps can be clearly perceived in the first loading phase. An interesting agreement can be noticed, especially when assuming $t_{g a p}=2 \mathrm{~mm}$ for the analytical calculations. Once the $n$ gaps are closed, the load-displacement response of the full-scale sample has mostly a linear trend, which is 
more pronounced in the analytical plots, where possible local defects/damage mechanisms in the carpentry joints are accounted in a simplified way, with respect to the experiment.

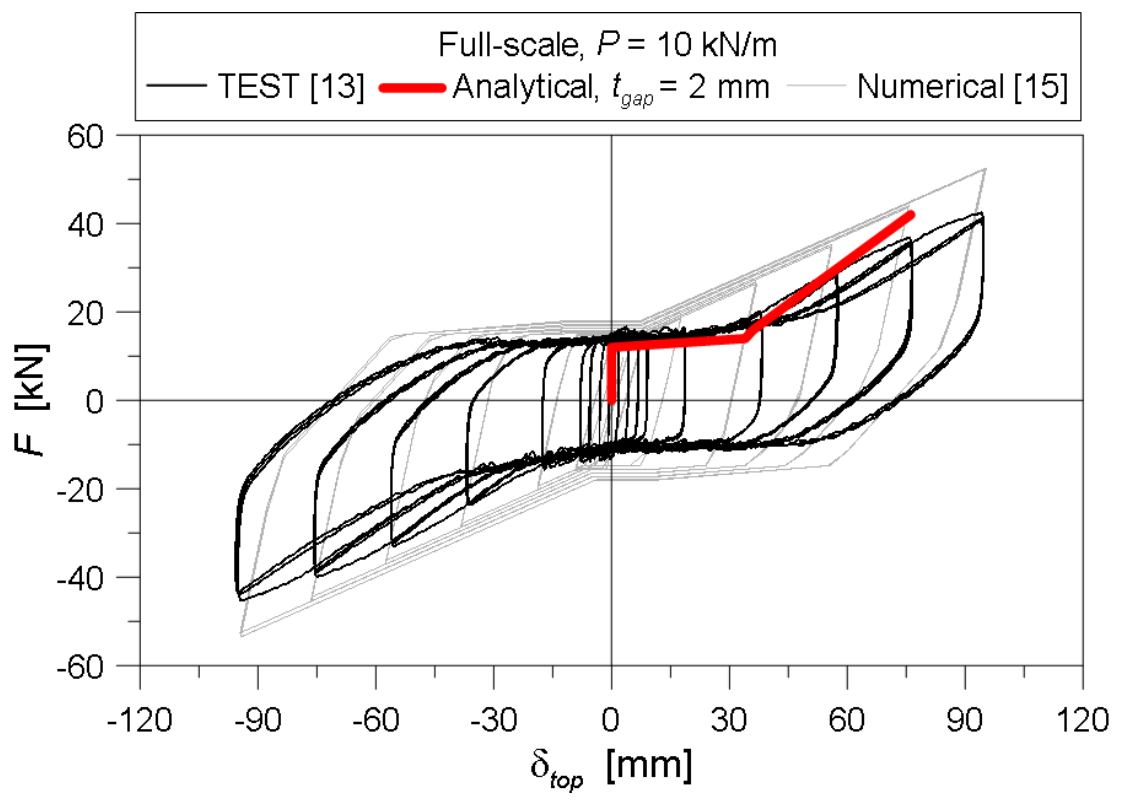

(a)

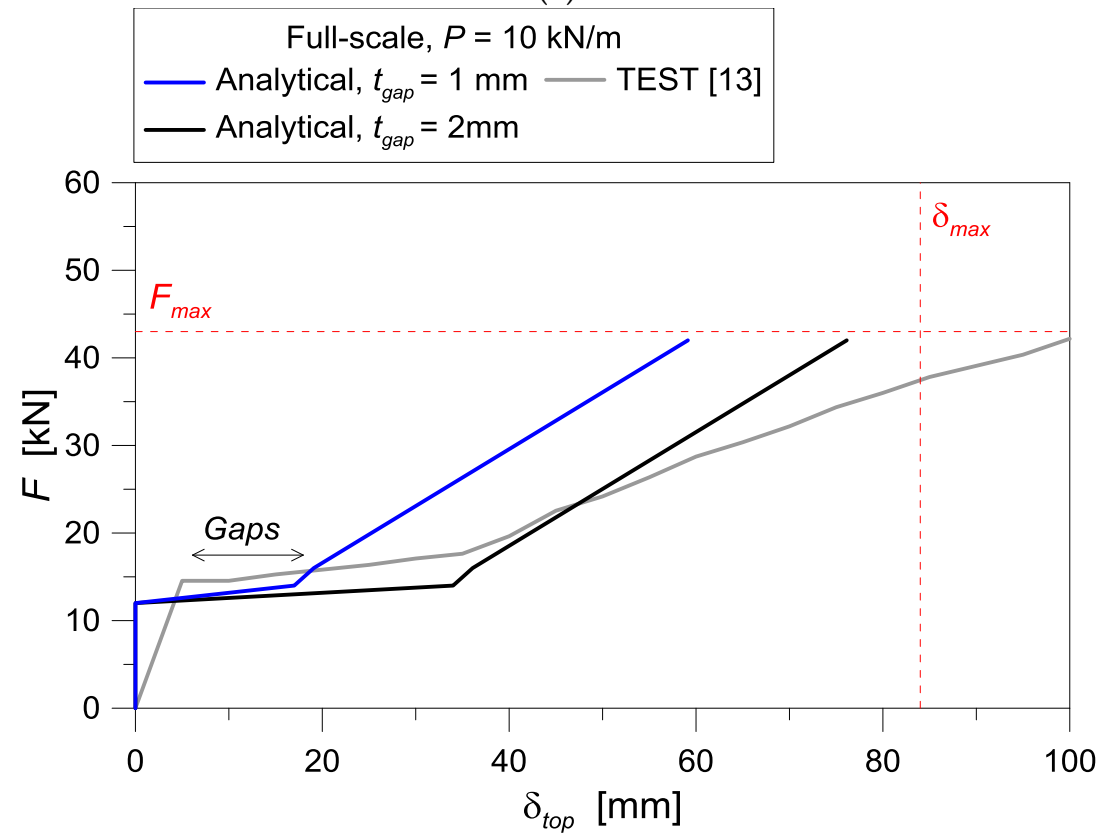

(b)

Figure 11. Comparison between the analytical model predictions, the past test results $[12,13]$ and the refined FE model presented in Reference [15] for full-scale log-house walls. (a) Cyclic and (b) monotonic performance assessment of the "M_ST_90" experimental sample $(L=4.20 \mathrm{~m}, H=2.80 \mathrm{~m}, p=10 \mathrm{kN} / \mathrm{m}$, Standard joints).

\subsection{Derivation of Force-Preload-Displacement Charts}

Based on the analytical formulation of Section 4.1, it is reasonably expected that several conclusions could be derived even from simple analytical calculations, as for example standardised charts in support of the design process, so as to obtain a reliable estimation of the expected shear wall lateral displacement for a given log-house assembly. 
In Figure 12, an example of the herein defined Force-Preload-Displacement ("FPD") charts for in-plane loaded log-house walls is proposed. Here, the imposed vertical compression spans from 5 to $10 \mathrm{kN} / \mathrm{m}$, while the other relevant parameters for the analytical model were assumed as in Section 4.2. The stiffness $K_{e l}$ of Standard joints was finally derived from Table 2 and Figure 9. In order to generalize the proposed charts, making them suitable and valid overall from the gap thickness $t_{g a p}$ (provided that the static friction coefficient and the wall geometrical features are kept constant), the analytical curves are proposed in terms of lateral deformation $\delta_{t o p}$, that is:

$$
\delta_{\text {top }}^{*}=\sum_{i=2}^{n} \delta_{i}
$$

In the design practice, similar charts can be used for preliminary assessment of wall in-plane lateral response under different compressive/lateral load design configurations, hence for the calculation of the expected lateral displacement. Further support is expected also in the opposite way, that is for the estimation of the maximum lateral load that a given log-house assembly could sustain, given its geometrical featuers. In the latter case, the required input data are the vertical preload and the maximum drift that the timber wall should not exceed (i.e., $3 \%$ at the Collapse Limit State, for example, according to Reference [30]).

It is also expected, in conclusion, that FPD charts could be further extended to a set of geometrical and loading configurations of technical interest for designers, to account for the presence of door/window openings, as well as for the presence — given a wall geometry—of multiple/intermediate joints (rounded dovetails, etc.).

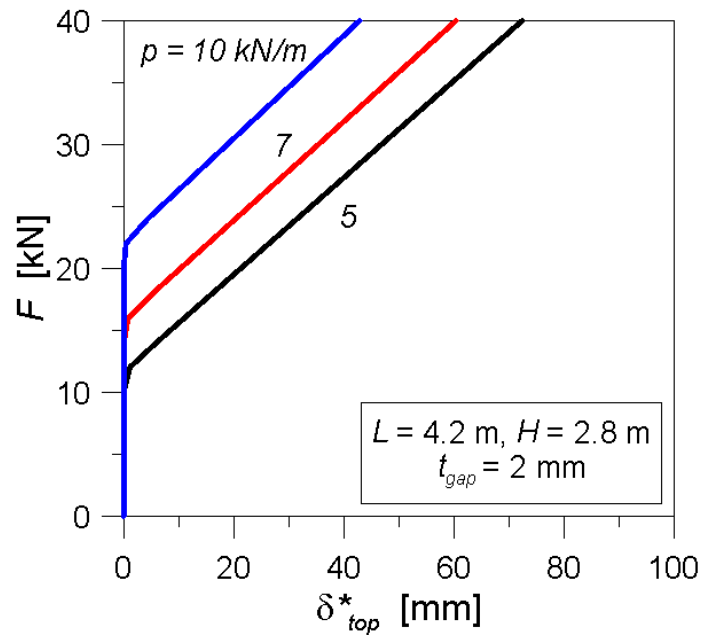

(a)

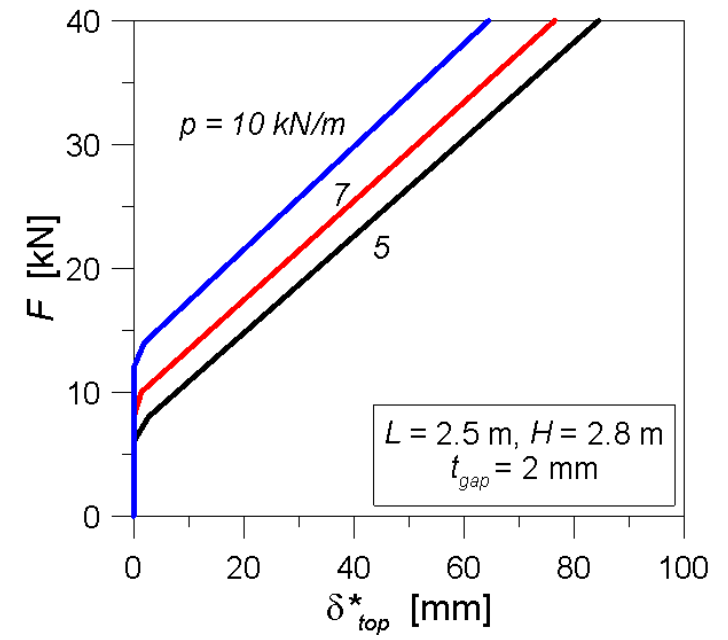

(b)

Figure 12. Example of "FPD" charts for log-house timber walls under in-plane lateral loads, with (a) $L=4.2 \mathrm{~m}$ and $(\mathbf{b}) L=2.5 \mathrm{~m}$.

\section{Conclusions}

In this paper, the in-plane seismic performance of log-house walls was explored via Finite-Element (FE) numerical models and simplified analytical formulations. As is known, the lateral response of log-house walls acting as load-bearing components in buildings is strictly related to the mechanical performance of the overlapping and intercepting logs, including sequential sliding effects and the progressive activation of corner joints.

Taking advantage of earlier experimental studies carried out on small-scale specimens representative of a portion of full log-house wall (i.e., corner joints), as well as past numerical efforts, full 3D solid FE models able to capture their actual mechanical performance were first described (ABAQUS). As shown, rather good agreement was generally found between the past experimental 
results and the FE numerical models, for selected corner joint samples. The same FE models were hence used to estimate the reference stiffness value for typical corner joints, being this value dependent on the joint features, on the loading configuration and on a combination of geometrical/mechanical input features (i.e., gaps, friction phenomena, etc.). Based on a short parametric study, their typical in-plane shear performance was hence numerically discussed, including sensitivity studies on their elastic stiffness.

A simple but accurate analytical model was hence presented for full-scale log-house walls, and validated towards past experimental and numerical outcomes, to provide a suitable tool for preliminary design considerations. A key role was assigned to several parameters, including the equivalent stiffness of joints (numerically estimated for several configuration of interest), as well as friction mechanisms and possible small gaps. The analytical curves generally exhibited a rather good compliance with past predictions of literature for full-scale log-house walls. Force-Preload-Displacement ("FPD") design charts were then also presented, to estimate the expected in-plane load-displacement response of log-house walls in shear, to act as a suitable tool in support of design.

Author Contributions: All the authors were involved collaboratively in the paper drafting and review. In particular, M.S. and C.B. conceived of and pursued the literature survey on log-house structural systems. C.B. took care of the FE modelling and parametric studies, while M.S. implemented the simplified analytical model. M.F. and A.L. supervised the overall project, being included in the Ph.D. project of the first author.

Funding: This research study received partial external funding from DPC-ReLUIS-Year 2017, within the framework of the 'PR4-Timber structures' Italian project. The APC was then funded by MDPI (voucher discounts for the second author acting as a reviewer for MDPI journals).

Acknowledgments: The research outcomes discussed in this paper follow and extend a previous project involving C.B., M.F. and Rubner Haus AG Spa. In this regard, a special thanks is for Daniel Gasser, Annalisa Battisti (Rubner Haus) and Maurizio Piazza (University of Trento, Italy), for providing technical data and support for the past experimental investigations.

Conflicts of Interest: The authors declare no conflicts of interest.

\section{References}

1. Eurocode 8-Design of Structures for Earthquake Resistance-Part 1: General Rules, Seismic Actions and Rules for Buildings; EN 1998-1:2004; European Committee for Standardization (CEN): Brussels, Belgium, 2009.

2. Eurocode 5-Design of Timber Structures-Part 1-1: General-Common Rules and Rules for Buildings; EN 1995-1-1:2009; European Committee for Standardization (CEN): Brussels, Belgium, 2009.

3. Heimeshoff, B.; Kneidl, R. Zur Abtragung vertikaler Lasten in Blockwänden-Experimentelle Untersuchungen (Carrying of vertical loads by walls of log houses). Holz Roh Werkst. 1992, 50, 173-180. (In German) [CrossRef]

4. Heimeshoff, B.; Kneidl, R. Bemessungsverfahren zur Abtragung vertikaler Lasten in Blockwänden. (Methods of calculation for walls of log houses under vertical loads). Holz Roh Werkst. 1992, 50, 441-448. (In German) [CrossRef]

5. Bedon, C.; Fragiacomo, M. Derivation of buckling design curves via FE modelling for in-plane compressed timber log-walls in accordance with the Eurocode 5. Eur. J. Wood Prod. 2017, 75, 449-465. [CrossRef]

6. Bedon, C.; Fragiacomo, M. Numerical and analytical assessment of the buckling behavior of Blockhaus log-walls under in-plane compression. Eng. Struct. 2015, 82, 134-150. [CrossRef]

7. Bedon, C.; Rinaldin, G.; Izzi, M.; Fragiacomo, M.; Amadio, C. Assessment of the structural stability of Blockhaus timber log-walls under in-plane compression via full-scale experiments. Constr. Build. Mater. 2015, 78, 474-490. [CrossRef]

8. Bedon, C.; Fragiacomo, M. Experimental and numerical analysis of in-plane compressed unprotected log-haus timber walls in fire conditions. Fire Saf. J. 2018. [CrossRef]

9. Bedon, C.; Fragiacomo, M.; Amadio, C.; Sadoch, C. Experimental study and numerical investigation of 'Blockhaus' shear walls subjected to in-plane seismic loads. J. Struct. Eng. 2014, 141, 04014118. [CrossRef]

10. Branco, J.; Araújo, J.P. Structural behavior of log timber walls under lateral in-plane loads. Eng. Struct. 2012, 40, 371-382. [CrossRef] 
11. Leichti, R.J.; Scott, R.J.; Miller, T.H. An experimental investigation of foundation anchorage details and base shear capacity for log buildings. For. Prod. J. 2001, 55, 4.

12. Giovannini, T.; Grossi, P.; Sartori, T.; Tomasi, R. Blockhaus system: Experimental characterization of corner joints and shear walls. In Proceedings of the World Conference on Timber Engineering-WCTE2014, Quebec City, QC, Canada, 10-14 August 2014.

13. Grossi, P.; Sartori, T.; Giongo, I.; Tomasi, R. Analysis of timber log-house construction systems via experimental testing and analytical modelling. Constr. Build. Mater. 2016, 102, 1127-1144. [CrossRef]

14. Branco, J.M.; Lourenço, P.B.; Aranha, C. Seismic analysis of a 2-storey log-house. Adv. Mater. Res. 2013, 778, 478-485. [CrossRef]

15. Bedon, C.; Rinaldin, G.; Fragiacomo, M. Non-linear modelling of the in-plane seismic behaviour of timber Blockhaus log-walls. Eng. Struct. 2015, 91, 112-124. [CrossRef]

16. Bedon, C.; Rinaldin, G.; Fragiacomo, M.; Noé, S. Finite element assessment of the seismic performance of three dimensional Blockhaus buildings. In Proceedings of the World Conference on Timber Engineering-WCTE 2016, Vienna, Austria, 22-25 August 2016.

17. Bedon, C.; Fragiacomo, M. Numerical Investigation of Timber Log-Haus Walls with Steel Dovetail Reinforcements under In-Plane Seismic Loads. Adv. Civ. Eng. 2018, 2018. [CrossRef]

18. Abaqus, F.E.A. V. 6.12 Computer Software; Dassault Systèmes: Providence, RI, USA, 2015.

19. Structural Timber-Strength Classes; EN 338; European Committee for Standardization (CEN): Brussels, Belgium, 2009.

20. FIP ${ }^{\circledR}$-Technical Data Sheet_Plastic Materials. Available online: http://www.fipitaly.it (accessed on 31 July 2018).

21. Murase, Y. Friction of wood sliding on various materials. J. Fac. Agric. Kyushu Univ. 1984, 28, 147-160.

22. Flatscher, G.; Bratulic, K.; Schickhofer, G. Screwed joints in cross laminated timber structures. In Proceedings of the WCTE2014-World Conference on Timber Engineering, Quebec City, QC, Canada, 10-14 August 2014.

23. Eberhardsteiner, J. Mechanisches Verhalten Von Fichtenholz; Springer: Wien, Austria, 2002; ISBN 978-3-211-83763-4. [CrossRef]

24. Bodig, J.; Jayne, B.A. Mechanics of Wood and Wood Composites; Van Nostrand Reinhold: New York, NY, USA, 1982.

25. Tomasi, R.; Sartori, T.; Grossi, P.; Wenzell, L. Blockhaus Structural System: Experiments on Corner Carpentry Joints; Internal Technical Report; University of Trento: Trento, Italy, 2012. (In Italian)

26. Giovannini, T.; Grossi, P.; Sartori, T.; Tomasi, R. Blockhaus Structural System: Experiments on Full-Scale Walls; Internal Technical Report; University of Trento: Trento, Italy, 2012. (In Italian)

27. Izzi, M.; Flatscher, G.; Fragiacomo, M.; Schickhofer, G. Experimental investigations and design provisions of steel-to-timber joints with annular-ringed shank nails for Cross-Laminated Timber structures. Constr. Build. Mater. 2016, 122, 446-457. [CrossRef]

28. Timber Structures. Test Methods. Cyclic Testing of Joints Made with Mechanical Fasteners; EN 12512:2001/A1; CEN: Brussels, Belgium, 2005.

29. Timber Structures. Joints Made with Mechanical Fasteners. General Principles for the Determination of Strength and Deformation Characteristics; EN 26891; CEN: Brussels, Belgium, 1991.

30. Prestandard and Commentary for the Seismic Rehabilitation of Buildings; FEMA 356; Federal Emergency Management Agency: Washington, DC, USA, 2000.

(C) 2018 by the authors. Licensee MDPI, Basel, Switzerland. This article is an open access article distributed under the terms and conditions of the Creative Commons Attribution (CC BY) license (http://creativecommons.org/licenses/by/4.0/). 